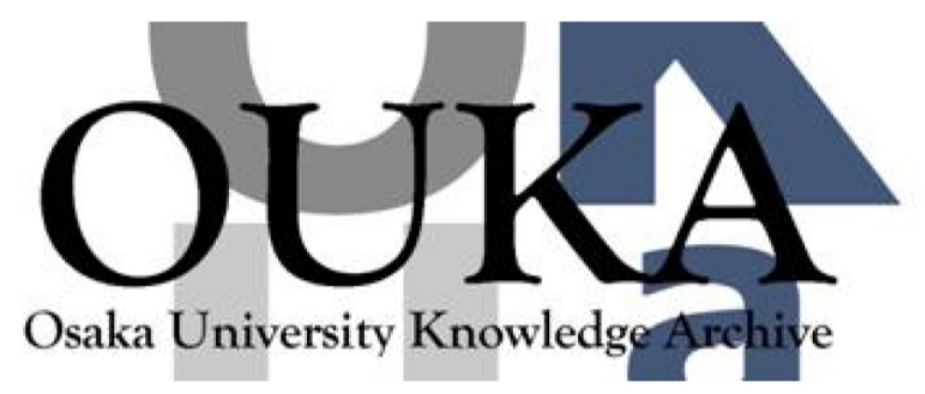

\begin{tabular}{|c|l|}
\hline Title & $\begin{array}{l}\text { The Paradox of Autonomy : Japan's Vernacular } \\
\text { Scholarship and the Policy Pursuit of "Super } \\
\text { Global" }\end{array}$ \\
\hline Author(s) & Ishikawa, Mayumi ; Sun, Chengzhi \\
\hline Citation & Higher Education Policy. 29(4) p. 451-p. 472 \\
\hline Issue Date & $2016-11-28$ \\
\hline oaire:version AM \\
\hline URL & https://hdl. handle. net/11094/61302 \\
\hline rights & \\
\hline Note & \\
\hline
\end{tabular}

Osaka University Knowledge Archive : OUKA

https://ir. Library. osaka-u. ac. jp/

Osaka University 


\title{
The Paradox of Autonomy:
}

\section{Japan's Vernacular Scholarship and the Policy Pursuit of "Super Global"}

\author{
Mayumi Ishikawa, Center for Global Initiatives, Osaka University \\ ishikawa@iai.osaka-u.ac.jp
}

Chengzhi Sun, Foreign Language Department, Dalian University of Technology

Acknowledgements:

This article is part of a comparative research project on "World-class Universities, Publication and Research Assessment: Rethinking the Mission of Higher Education in the Global Age" funded by the Worldwide Universities Networks (RDF/WUN Ref.: 4930217). 


\title{
The Paradox of Autonomy:
}

\section{Japan's Vernacular Scholarship and the Policy Pursuit of "Super Global"}

\begin{abstract}
Japan's humanities and social science scholarship has retained its commitment to the national language and local readership over the past two decades despite a policy-driven shift away from the old norm of distinctive independence once termed "opting out" of the game. Analysis of academic publications in two disciplines in a public research university from the 1990s to the early 2010s indicates little change in language or medium: an overwhelming majority are written in Japanese and published in national periodicals and books. The article unveils the paradox of autonomy in Japan's academia by examining the continued commitment to locally relevant research at the expense of global recognition vis-à-vis the government's declaration to make some of the nation's top universities "super global". Amidst the global fad to join the ranks of the world's top-ranked universities, the Japanese government's quest is likely to bring mixed consequences for domestic higher education institutions. In particular, the study points out an increasing risk of compartmentalization and erosion of vernacular research that demands a serious policy reappraisal.
\end{abstract}

\section{Key words}

World university rankings, world class universities, academic publishing, vernacular scholarship, humanities and social sciences, research assessment, Japan

\section{Opting out? Japan's prolific yet parochial academic publishing}

In his critical analysis of academic dependency, Alatas (2003) referred to the distinctive independence of Japan's social science scholarship as "opting out" of the game. The "game" here denotes the method of measuring academic success by publications in Western periodicals and in English, which is a prevalent way, Alatas argued, particularly in Third World academia, to gain prestige. While much influenced by Western ideas and models, Japan's social sciences nevertheless have remained committed to and reward publications in the national language in nationally recognized periodicals. Alatas thus considered Japan a possible alternative to Western dominance in the social sciences. 
Alatas's argument is supported by an earlier work of Lie (1996, Chapter 8). In an appendix to his Trend Report in Current Sociology, he discussed the status of academic production in contemporary Japanese sociology. Among many salient features, Lie pointed out a profusion of publications produced by a sizable local scholarly community (Japan has the second largest national sociological association in the world) in academic journals, department publications, publicly circulated periodicals and interdisciplinary journals, books and edited volumes, as well as a large number of translated works of Western classics and monographs, all in Japanese. Rich and diverse as they might be, these works "remained under the thrall of Western sociology" (Lie, 1996, 60) yet were out of reach for non-Japanese readers due to language accessibility.

\section{Vernacular scholarship and the global race for "world class"}

Both of the accounts above were made before the proliferation of various world university rankings, being spearheaded by Shanghai Jiao Tong University's Academic Ranking of World Universities launched in 2003. Such institutional rankings and their popularity are among the most prominent destabilizing factors to the status quo of humanities academic publishing and the system of vernacular scholarship in Japan. By and large, humanities and social science scholarship in Japan has, until today, kept the autonomous features observed by Lie in the mid-1990s. Pressure for change, however, is intensifying both outside and inside Japan.

Externally, intensifying global competition for excellence and state interventions to create “world-class" universities (see for example, Altbach and Balán, 2007; Huisman, 2008, and for Asia, see Guo and Ngok, 2008; Kim and Nam, 2007; Lo, 2013; Mohrman, 2008; Mok, 2012; Oleksiyenko, 2014; Shin, 2009; Song and Tai, 2007; Sidhu, 2005) is fueling an "academic arms race" (Hazelkorn, 2008, 209; Slaughter and Cantwell, 2012, 600-601). Internally, a 
preferential funding scheme by the Japanese government effectively instructs leading research universities to proactively become "Super Global" and improve their standings in the world university rankings (Ishikawa, 2014; Kariya, 2015).

The quest to improve institutional rankings often involves initiatives to steer faculty to focus on publishing in internationally indexed journals. Such measures, decided either by the government or university leaders, are often unpopular among humanities and social science scholars and considered problematic because they may undermine vernacular scholarship (see Chou, 2014; Huang, 2009; Lee and Lee, 2013 for examples from Asia). There are also problems inherent in using bibliometric indicators such as citations and impact factors in order to measure research quality (see for example Anninos, 2013; Dolan, 2007, 25-28; Scott, 2012; van Raan, 2005) and, by extension, institutional quality (Wright, 2012). However, ambitious universities in emerging economies such as China and Brazil are said to be pursuing improvements in such indicators with an awareness that they would "do better in the numbers-driven race rather than opinion-influenced race" (Oleksiyenko, 2014, 492). Increased publication productivity not only can lead to gaining prominence in the rankings but is also often viewed by universities "as a more attainable target than Nobel Prizes and Field Medals" (Oleksiyenko, 2014, 500).

As neoliberal policies and ideologies have proliferated, issues of accountability and audits have become dominant in higher education systems throughout much of the world (Shore and Wright, 1999; Strathern, 2000). ${ }^{1}$ The resultant numbers-driven race has created a "perverse colonizing effect" (Scott, 2012, 115-116), compelling followers to adhere to standards determined by the metrics. This effect is further strengthened by the propagation and popularity of various world university rankings. 


\section{Japan: Between autonomy and global aspiration}

Against such a backdrop, this article critically analyzes academic publishing in Japan over the past two decades in the context of recent national higher education policy development. We selected two fields of anthropology and educational policy for a pilot study in a research university and collected total article outputs during three reference years of 1993, 2003, and $2013^{2}$. Empirical data was augmented by interviews with junior and senior faculty from the same disciplines. The data indicates that, the state of publications for humanities and social sciences in Japan is relatively static, especially when compared with the drastic changes in the evaluation of academic publishing in neighboring countries that now prioritizes publications in internationally indexed journals (see for example, Chou, 2014; Lee and Lee, 2013; Li and Flowerdew, 2009; Lo, 2013; Shin and Cummings, 2010; Oleksiyenko, 2014; Stack 2016, 17; and contributions in this issue). Yet Japan's case exhibits highly contextualized and locally specific patterns and practices of academic publishing. There are also signs of a policy-driven shift away from the "opt-out" past. The resultant data and interview accounts identify subtle yet emerging changes in publishing trends in Japan and outline diverging aspirations among different generations of scholars.

In the next section, the research scope and design are first introduced, followed by a summary of the major findings and an analysis. We then turn to a discussion of the impending question of the sustainability of the "opting out" paradigm amid growing questions around the autonomy of humanities and social science scholarship and recent higher education policy development that prioritizes international competitiveness. What are the implications of the establishment of government-sponsored "Top Global Universities" (locally called "Super Global Universities") project in Japan, and the division of all national universities into the three categories of global, local, and specialized? These policies inevitably change the ways that operational and research funds are distributed and university audits are conducted, thus 
profoundly affecting the future course of vernacular humanities and social science scholarship in Japan. Although enhancement of global research engagement may be desirable over the long term (Mathews, 2015), the authors point out the risk of "compartmentalization" (Hanafi, 2011) by stratifying the national university system through uneven restructuring of local academia. Furthermore, the creation of "global universities" by adhering to a narrow definition of science and scholarship, "namely one that can be captured by Anglophone neoliberal audit cultures" (Jöns and Hoyler, 2013, 57), may improve the ranking positions of Japanese universities in the short term but it risks de-contextualization (Kang, 2009), the demise of long-sustained local scholarship, and the loss of autonomy in vernacular knowledge production.

The article in the end critically questions a policy quest or "policy panic" (Stack, 2016, 110) for global recognition triggered by the proliferation of rankings and the "world class university game" (Slaughter and Cantwell 2012, 601). The race for world class status prescribes the adherence to "excellence" indicators used by rankings rather than what is important for higher education (Hazelkorn, 2013). Our case study from Japan illustrates that "narrowly Anglo-American" (Paasi, 2005) international English-language publication data omits significant segments of Japan's academic research, and is thus unfit to accurately assess the performance of scholars in Japan (see also Ishikawa, 2014).

\section{Research design and scope}

The research done for this article is part of a larger comparative research project that documents and assesses academic publishing trends over the past 20 years in different countries by focusing on a publically-financed research university from each participant country, including Japan (see Preface, this issue). In line with the project's methodology, the 
authors conducted a quantitative survey of journal articles published by faculty of a national research university during the reference years of 1993, 2003, and 2013 in order to capture the changing and unchanging dimensions of academic publishing in Japan. Subsequently, interviews with junior and senior faculty and examination of relevant literature and policy documents were conducted to supplement the data analysis. The journal survey was preceded by a study of the status of academic publishing in Japan, which provided an overview of the trends in scientific publication in relation to the nation's institutional audit system (Ishikawa, 2014). In addition, the problems associated with blanket application of standardized and monolingual parameters used in rankings were examined using an ethnographic approach based on long-term participant observation at a non-English university (Ishikawa, 2009). While referencing these findings, the focus of this article is to present concrete and empirical evidence in order to analyze changes in academic publishing in a particular local context.

The research site for the study is a national university, one of Japan's leading comprehensive research universities listed in most world university rankings and league tables. The university has some 24,000 students and 3,000 faculty members. It is known for its prominent medical and engineering faculties; smaller but reputable humanities and social science faculties constitute roughly 20 percent of the total faculty. The university is fairly representative of Japan's seven former imperial universities that have served as the backbone of the nation's postwar economic success and scientific innovation. As such, the university is research-oriented, and faculty is expected to adhere to high standards of research outputs both for appointment and promotion. As a recipient institution of the "Top Global Universities" project, the university proactively promotes internationalization strategies both in research and education. If Japan shows any sign of producing an increasing number of internationally recognizable research articles in humanities and social sciences, it should manifest first in a leading institution such as this chosen research site. 
We identified faculty members in the fields of anthropology and education policy at the university in 1993, 2003, and 2013 and created a directory of their total article outputs up to June 2013. These two key fields and the time frame are consistently used for the comparative research noted above. It addition, unlike more English-language-based and thus internationally visible disciplines such as economics, psychology, and business administration, these two disciplines more or less represent the general trends in humanities and social sciences academic publishing in Japan (Hayashi and Tsuchiya, 2016, 334. See also the "Delayed Internationalization" section below). In the field of anthropology, the directory covers a total of nine scholars and their 302 articles (an average of 33.5 articles per scholar). For education policy, a total of 684 articles by ten scholars (an average of 68.4 articles per scholar) were collected and tabulated. ${ }^{3}$ Subsequently, all the data was classified according to eight categories and tabulated to track changes over the two decades (see Tables 1 and 2).

Following the article survey and tabulation from May to July 2014, semi-structured interviews were conducted in June and July 2014 with six scholars, one each from anthropology and education policy, as well as four junior scholars in education policy and higher education. The results of a recent study commissioned by the Japanese government on the internationalization of humanities and social sciences in five key disciplines were also referenced.

The articles are listed in the CiNii Articles database made available by the National Institute of Informatics, Japan. As noted, international journal databases such as Web of Science (WoS) do not capture the predominant proportions of research results in humanities and social sciences in Japan (cf. Hayashi and Tsuchiya, 2016, 333). The CiNii, which is the nation's largest and the most comprehensive publically sponsored directory for academic titles, is thus used for the analysis. It should be noted that the articles listed in the CiNii database are not equivalent to peer-reviewed academic journal articles such as those listed in SSCI by 
Thomson-Reuters. Japanese humanities and social science scholars often publish, or in fact prefer to publish, for the broader public in generalist and/or interdisciplinary periodicals for better visibility, impact, and prestige (cf. Lie, 1996, 59-60). While scholars in research universities tend to produce more publications for academic and professional journals, some of their works are also published for the broader public, policy-makers, and national intellectual readership. As it is hardly possible to distinguish one from the other, we consistently use the same database. Our case study is thus meant to track changes of publishing practices within Japan. We also capture changes in publishing practices by the same scholars over time, and among different generations of scholars.

\section{Major findings and analysis}

\section{Overview}

First, the major findings of the study are summarized below, followed by quantitative and qualitative analysis and observation.

1. Japanese humanities and social sciences scholars did not change their publishing practices in a significant way from the 1990 s to the early 2010 s. Analysis of research articles in two disciplines indicates little change in authorship, language or medium: an overwhelming majority are single-authored articles written in the Japanese language and published in local (national) journals and periodicals.

2. In anthropology, articles with bilingual titles and abstracts, typically in Japanese and English, have become common over the past decades. Though articles are predominantly published in the Japanese language in domestic journals, anthropology is considered a "global discipline" in inputs and research orientation in Japan. 
3. Education policy is more locally embedded in medium and in content. The education scholars in this study primarily published for the national scholarly community and intellectual readership. However, international contents such as comparative analyses with other countries or internationalization of local schools have become more common in recent years.

4. Books are consistently favored over articles. Articles in academic journals are often considered milestones to publishing books. Books are more accessible for the general public than are professional journals, thus having better outreach and more significant social impact. For these same reasons the scholars in this study, particularly those in education policy, published articles in intellectual journals, popular magazines, government bulletins, and newspapers.

5. Both senior and junior scholars acknowledge the growing importance of publishing internationally and predict an increase in English-language publications. Young scholars are more willing to publish articles in English in international journals. For young scholars, international research outputs and expertise (for example, presenting papers at international conferences and participating in international research collaboration) are becoming a requirement for obtaining faculty positions in research universities. Despite this, English and Japanese articles are evaluated equally under current academic norms and practices. Young researchers interviewed are therefore often torn between writing one English article and producing more higher quality articles in Japanese.

6. Senior scholars publish in English in international journals as an outcome of international collaboration or by invitation. At least among those interviewed for this study, no reference was made to strategically choosing certain prestigious journals such as those listed in SSCI for recognition. 


\section{Journal article survey}

Journal articles were classified according to the following eight categories in each reference year: 1) Co-authorship, 2) Title Language, 3) Title Relevance, 4) Title Geographic Category, 5) Abstract Language, 6) Journal Language, 7) Journal Origin, and 8) Journal Geographic Category. ${ }^{4}$ Table 1 details the anthropology articles and Table 2 details those in the field of education policy.

[INSERT TABLE 1 and TABLE 2]

In both fields, Japanese scholars publish predominantly single-authored articles in journals published in Japan for the national audience (see Co-authorship, Journal Geographic Category, and Journal Origin). Across all reference years, over 97 percent of articles were published in national journals, and over 92 percent in the Japanese language.

In the field of anthropology, there was a small yet notable increase in the number of articles published in English from almost none (1.5 percent in 1993) to about 7 percent in 2003 and 2013 (see Journal Language). Education policy scholars, however, have kept their national focus of research intact, with the proportion of English journal articles, despite a small increase, remaining a meager 2.4 percent of the total in 2013.

Concerning total and per scholar publications, 1993 figures well exceed the other reference years in both fields. This is due to the presence of two highly productive and long-serving scholars, one in each field, who were faculty in 1993, who have subsequently served many prominent positions in different institutions. The high figures in 1993 thus do not necessarily indicate a general decline in productivity in the following years. Also, publication patterns are 
specific to discipline and different between the two fields studied. An education scholar interviewed ascribed the higher number of articles generated by education scholars to the fact that the field has many subdivisions, and consequently more academic journals, when compared to other disciplines.

An English-Japanese title and abstract listing has become the norm for anthropology. This trend corresponds to the increase in the number of articles with English abstracts in the discipline. The percentage of article titles written only in Japanese has decreased from 83.7 percent in 1993 to 59.5 percent in 2013, and titles in two languages, most typically in Japanese and English—even when most articles are written in Japanese_-increased from 16.3 percent to 40.5 percent over the same period. A similar trend is harder to establish for education policy.

Regarding the local relevance of the articles (Title Relevance and Title Geographic Category), both disciplines exhibit a similar trend of increase in non-Japan focused content. In the field of anthropology, the proportion of nationally focused articles was already modest at 20 percent in 1993. This subsequently declined to 5.1 percent in 2003 and 3.6 percent in 2013 . In education policy, nationally focused content also decreased, from about 76.7 percent in 1993 to 59.2 percent in 2013.

Anthropology is considered an "international" or "non-national" discipline in Japan, distinguished from locally focused ethnographic, historical, and cultural studies, which are usually classified as "folklore" studies. The percentage of research with borderless and non-Japan focused content, both in Title Relevance and Title Geographic Category, exceeded 90 percent for anthropology in 2003 and 2013. Higher nationally focused publication figures for 1993 scholars do not necessarily demonstrate a growing interest in international content. Rather, it is considered a reflection of older scholars gradually retiring from fieldwork 
overseas and shifting to domestic issues. Similar to their American counterparts, Japanese anthropologists started engaging in ethnographic research on societies all over the world in the 1970s thanks to economic development and growing affluence (Mathews, 2015, 366). The field has thus become "global discipline" in inputs and research orientations, if not yet in outputs.

Education policy, on the other hand, has solidly retained its national, local focus. A close examination of the list of complied articles shows an unchanging commitment to national educational policy issues by scholars in this discipline. The majority of the articles focus on education scholarship in Japan without a major change over the past two decades. A growing percentage of articles, however, include content about other countries (1.2 percent in 1993 to 32 percent in 2013), and consequently the percentage of articles written only about Japan has decreased from 76.5 percent to 55.6 percent over the same period (see Title Geographic Category). The figures may demonstrate education scholars' growing interest in international research topics. Even in cases where research is classified as "national," a closer examination reveals an increase in international research contents, such as comparative analyses of the education systems of Japan and Europe, assimilation of foreign school children in Japan, and other topics with international and comparative perspectives.

The article survey in two key fields thus captures little change over time in the language and the medium of publications with any notable changes in content rather than outlet. Our qualitative research, however, showed emerging, nuanced changes in the aspirations of different generations of scholars in Japan.

\section{Signs of change}

A comprehensive report concerning the "internationalization of humanities and social sciences" in Japan, released by The Japan Society for the Promotion of Science (JSPS) in 
2011 (JSPS, 2011), criticized a "lack of ambition" on the part of Japanese humanities and social science scholars who have thus far remained "buyers rather than producers" in the international academic market (JSPS, 2011, 2). The working group that undertook the two-year study commissioned by the Ministry of Education, Culture, Sports, Science and Technology of Japan (MEXT) selected five key disciplines of Asian history, sociology, law, politics, and economics. The study was detailed both quantitatively and qualitatively, and included an analysis of bibliometric indicators on publications and citations, a study of publication trajectories of internationally renowned Japanese scholars, an assessment of weaknesses and strengths in each field, interviews and the results of focus group meetings with Japanese and non-Japanese scholars, and a review of the status of international research networks and collaboration.

Interviews conducted with senior and junior scholars for this study largely confirm rather than contradict the findings outlined in the JSPS report. All senior and junior scholars agreed that it is increasingly important to publish internationally and in English, particularly for younger scholars in humanities and social science fields. A senior education scholar in his mid-50s stated that for his generation, all scholarly training and works were done in Japanese. He has written articles in English and published them internationally only on two conditions: as an outcome of international collaboration or joint research, and upon an invitation to contribute to an international conference and/or a special issue of a journal or an edited volume. He noted, however, that more scholars in their $40 \mathrm{~s}$ and younger have overseas degrees and working experiences, and the number of English-language articles and books has been increasing. He says, "It used to be the case that only foreign scholars such as William Cummings and Ronald Dore wrote about Japan's education in English. Such works were subsequently reintroduced to Japan and became well known. Now, more works are written in English by Japanese scholars about Japanese education, some as members of international 
research teams".

Speaking about the general publication trends in anthropology, a senior anthropology scholar in his 60s says that academic publication over the past two decades has not changed significantly. There has, however, been "some increase" in the number of international conference papers by Japanese scholars. He promotes the internationalization of a professional association he belongs to and stresses the importance of internationally visible and relevant research. As part of such efforts, the association recently hosted a major international conference in Japan, during which a roundtable was organized with aims such as strengthening the capacity of Japanese scholars to publish more internationally. Awareness concerning the importance of publishing internationally has thus been rising among local anthropologists. In addition, public funding is gradually shifting away from purely domestic journals to those with more international appeal and outreach, and those written in English.

The senior anthropologist obtained his doctorate degree from a leading American research university but found that his qualification was not easily valued in the earlier days of his career in Japan. A senior education scholar shared the similar observation: "For a long time, Japanese academia underappreciated foreign $\mathrm{PhDs}$. This is because thirty years ago, only very senior scholars in humanities and social sciences were given a doctorate in Japan, usually just before retirement as recognition of lifetime achievement. A Japanese humanities doctorate was therefore only for a very limited number of top scholars who had achieved both success and fame". Now that has completely changed as more young scholars are given degrees upon completion of their graduate training. While this trend is positive, the education scholar also points out that some graduate students today are reluctant to study overseas. Not only has it become easier to receive a doctorate degree in Japan, but some consider it easier to get a job with a domestic degree and domestic personal connections. 
Yet according to a senior anthropologist, all junior colleagues recently appointed in the anthropology department have some international experiences, credentials or expertise. According to another senior scholar, it is difficult to find a position in a research university today without international capacity and/or the ability to actively engage in international research groups or networks.

An education scholar in his 40s who studies European education systems says he has published several articles in a European (non-English) language. This facilitates his research by introducing his work and interests to local people and scholars. He adds that publishing in a foreign language and in foreign journals is a definitely a plus due to the benefit of seeing one's own research objectively.

This same scholar observes that the overall internationalization process proceeds rather slowly because "Japan has an established (academic) market and academic associations based on the Japanese language". He mentions, however, that "the degree of internationalization depends on the specific field within education studies" and, citing a recent example of a comparative study of education curricula in China, Korea and Japan, that "there is some internationalization developing within Asia, with the Japanese language as a medium".

All younger scholars confirmed the importance of publishing internationally and professed their desire to do so, despite apprehension about the difficulties involved. None imagine that their future research career can be adequately constructed simply by publishing in Japan in domestic journals and books. However, considering the fierce competition among young scholars for university faculty positions, one young scholar said it might be wiser to publish three articles in Japanese rather than publishing one in English, as an English article might be highly evaluated but may not provide the same rewards, despite the time and effort, as a number of quality academic articles written in Japanese. One young scholar mentions, "A 
scholar's robustness is evaluated by the number of academic papers, not by the language used".

This point, however, was refuted by two senior scholars in education and anthropology. The education scholar comments on "a worrisome trend" of fierce competition and says, "Both number and quality matter. But young people are number-oriented. Some just produce more articles by thinning the contents". The anthropology scholar agrees: "After all, it is quality. But not the quality measured by (journal) Impact Factor". Similarly, none of the young scholars interviewed consider journal Impact Factor as relevant for their evaluation.

Concerning just how much leverage articles published in English in international journals offers, there seems to be a lack of consensus among junior scholars, resulting in differing strategies among individuals. One interviewee describes a fellow young scholar who, despite no real pressure from his supervisor to do so, prioritizes publishing in English, thinking it is the only way to be recognized.

In addition, senior scholars and junior scholars alike consistently favor publishing books over articles. Japanese scholars generally consider articles in academic journals as milestones to publishing a book. Sample book data, which we collected from four senior scholars, two each from the selected disciplines, is instructive (see Table 3). Books, to this day, have remained "the most prestigious and most effective media for disseminating ideas" (Lie, 1996, 60). Two senior scholars who were among the faculty in 1993 (A and C in Table 3) still publish and remain prolific, though more as "public intellectuals" rather than writing pure academic articles and books later in their career. The data from two others (B in Table 3 was faculty in 1993, and D in 2003 and 2013) also indicates a strong preference to publish books. 


\section{“Delayed internationalization"}

According to the JSPS report and interviews conducted for this study, the major constraints for Japanese humanities scholars to publishing their work internationally are: language, differences in publication protocol and practice, and lack of rewards and incentives to publish in English (see also Yonezawa, 2012). Some critiques also question the quality of graduate education in Japan, especially the poor quality of scholarly language training as part of postgraduate training. In addition, an established and sizable national academia and intellectual readership ensures the viability of a national market for books and articles. An accumulation of Japanese-language books, articles, and a large number of translated works of major Western classics and monographs from pre-war periods also enable the continuation of research tradition and scholarly training in the national language.

Japan arguably has one of the most autonomous higher education and research systems in the non-Western world. This is due to the nation's history, the use of the national language for all levels of education, and, with exception of the period immediately following the establishment of the modern university system in the late 19th century, an independent system of training university faculty without requiring them to attend Western institutions to attain higher degrees or garner prestige (cf. Amano, 2009). According to the JSPS report (JSPS, 2011, 148), internationally known Japanese political scientists published English articles such as those listed in Web of Science (WoS) only while they had faculty positions in universities overseas. Upon their return to Japanese universities, they stopped producing articles in English, indicating the lack of incentive to continue to do so. This point, that English articles might be highly evaluated at the time of faculty appointments but not necessarily thereafter, was repeatedly raised in our interviews. The JSPS report also points to little time allocated for 
research for Japanese scholars as another possible cause for not publishing in international journals.

As of 2009 , some 400 of the approximately 2,000 academic journals published in Japan were in English (MEXT, 2012, 40). The majority of these were in physical science fields, with only 16 percent covering humanities and social sciences. Although the representation of humanities and social science journals remains small, English journals in these fields have increased twofold since 2003 (MEXT, 2012, 40). The number of Japanese scholars who publish in WoS-listed humanities and social sciences journals has increased by nearly 10 percent over the five years, if not their shares in the total output (Funamori, 2012, March 6, slide 13).

The overall trend of "delayed internationalization" in humanities and social sciences does not necessarily apply to other fields, as publication practices differ markedly among disciplines. Hayashi and Tsuchiya (2016) studied all the journal articles submitted for the first "Evaluation of Education and Research at National Universities" conducted in 2008 to analyze the proportion of articles indexed in WoS by field. The articles in their study supposedly represent the best research outcomes selected and submitted by participating departments and faculty of all national universities in Japan. While 90 percent of all articles submitted in medical, dental, and pharmaceutical sciences were listed in WoS, a rather modest figure of 65 percent of those in engineering was indexed. By contrast, only 2 percent of humanities articles were WoS indexed; less than 3 percent for most areas of social sciences, including anthropology, geography, law, politics and sociology were listed, with the exception of economics (46 percent) and psychology (37 percent).

International bibliometric indicators such as WoS or Elsevier's Scopus, adopted by most ranking institutions to measure research quality, thus capture only a fraction of humanities and social science research in Japan, except in a small number of fields. The international 
bibliometrics have thus far remained rather irrelevant for the majority of humanities and social science scholars in Japan, if not for their counterparts in the physical or natural sciences (Ishikawa, 2014). Compared with scholars in the natural and physical science fields, who have been awarded the second highest number of Nobel Prizes after American scientists since the beginning of this century, are their humanities counterparts still "opting out" of the game?

\section{Global ambitions and the reform of national research universities}

\section{Becoming "Super Global"}

Throughout much of the past century, Japanese universities have practiced a "policy of indigenization" (Amano, 2014). Consequently, in a relatively short period of time after their establishment in the late $19^{\text {th }}$ century, universities in Japan successfully achieved autonomy from their dependence on the West. This "indigenous" tertiary education system has produced a skilled workforce in an efficient, inexpensive manner, contributing to the modernization and industrialization of Japan (Amano, 2014). This same success, however, has now become a burden for the nation faced with the challenges of globalization.

Various higher education internationalization policies have been implemented by the government since the 1980 s, only to be strengthened since the beginning of the new millennium (Ishikawa, 2011; Ninomiya et al., 2009), especially after national universities became incorporated as independent administrative and legal entities in 2004. As noted at the beginning of this article, the prevalence and popularity of various world university rankings, which have incidentally "arisen in parallel with the corporatization of Japan's national universities" gave pertinence to the arguments to reform and strengthen the country's research universities, particularly national research institutions (Amano, 2014). The national universities, though fewer than 90 in number, are among the best of nearly 800 universities in 
Japan in academic research and professional education. Not only do they account for 57 percent of master's students and 69 percent of $\mathrm{PhD}$ students nationwide, they are also the highest positioned institutions in most world university rankings and league tables (Amano, 2014). National research universities thus epitomize Japan's excellence in research and education, positioned at the core of national competitiveness policy discussions.

A notable recent policy to internationalize universities to "raise their international competitiveness" is the "Top Global University" project, locally called "Super Global" and launched in 2014. A total of 37 universities nationwide are awarded competitive grants for up to ten years for their internationalization initiatives. Of these, thirteen are named "Top Type" with "the potential to be ranked in the top 100 in world university rankings" and given a larger share of funding. The project was conceived after the former MEXT minister $\mathrm{H}$. Shimomura announced in 2013 that his ministry wanted to see at least ten Japanese universities among the world's top-ranked 100 universities within the next ten years.

Selected universities are committed to improve their standings in the rankings and thus ambitious in their plans and objectives. Application documents, prepared by universities in accordance with the required standards prescribed by the MEXT, are awash with initiatives to increase the number of international students and staff as well as course offerings in the English language, to internationalize curricula, admission processes and administration, and strengthen international dimensions of education and research by promoting international exchange, joint research and supervision, just to list some examples.

What is strangely lacking or downplayed in the Top Global application documents, however, are concrete plans or clear targets for increasing the number of academic publications in internationally indexed journals, a common and prevalent strategy for research universities overseas with ambitions to be ranked among the top universities worldwide. Only Keio 
University, a private and leading comprehensive university, refers to their plan to encourage scholars to publish in international journals listed in the WoS. Initiatives by other universities in this area are rather vague, such as to encourage and increase the number of internationally co-authored articles so as to improve citations and reputation scores, or to translate and publish faculty research into English by collaborating with the university press. Compared with the time-bound, specific, and quantitative goals required for the internationalization of the student body, faculty, and education content, as well as administration reforms, the issue of publishing research outputs internationally in indexed academic journal articles seems to be rather peripheral to the concern of ministry officials and university leaders.

\section{New "global-type" universities and a risk of compartmentalization}

While universities across the globe that seek recognition as "world-class" are intent on strengthening their performance in the numbers-driven race by incentivizing and rewarding journal publications, Japanese counterparts seem to be more focused on improving international public relations, diplomacy, and outreach in their paths toward "Super Global".

Such inclinations, specific to Japan, have not emerged out of the government's concern for vernacular scholarship, especially in the humanities and social science fields. In June 2015, the MEXT informed all national universities to plan and implement radical reform measures to the point of "overhauling" their existing structures during FY2016 to FY2021. ${ }^{6}$ The notice included a clause suggesting an organizational restructuring that might lead to the abolishment of faculties and schools in humanities and social sciences, or their conversion to "areas with greater demands from the society". A nationwide uproar and voices of protest against the ministry's "move to abolish humanities and social sciences from national universities" ensued (see for example, Sawa, 2015, 23 August). Statements of protests from academic and professional societies (even from the Japan Business Federation), media stories, 
and special issues in influential periodicals such as Gendai Shisō [Contemporary Thoughts] and Chūō Kōron [Central Public Opinion] seem to have created a national movement in defense of education and research in the "under-appreciated" disciplines. ${ }^{7}$

While the public and media attention has focused on the future of humanities and social sciences, the government's plan for a "period of accelerated reform" has proceeded. By September 2015, all national universities were classified into one of three new categories—local, specialized, or global—depending on each university's choice. "Local" institutions contribute to the local society through human resource development and solving problems that local communities face, while conducting national and global-level research and education in specialized areas. "Specialized" universities are those that offer fine arts, medicine, foreign languages, science and technology, and other specialties, and pursue nationally and globally competitive research and education in specific areas of their expertise. "Global" institutions are those that can compete with excellent universities overseas and conduct world-class education and research throughout all faculties within the university. All universities will be allocated operational funds and evaluated based on their chosen category. Of 86 total national universities, sixteen chose Type 3, or the global category; ten of those coincide with the "Top Type" institutions selected for the Top Global University project. ${ }^{8}$

The implications and consequences of this new typology for the funding and evaluation of Japanese national universities are yet to be seen. What is already clear, however, is that the new stratification mechanism adheres to global denominators of excellence, a departure from the existing local norms of excellence and prestige. There is no denying that a degree of hierarchy has always existed in Japan's higher education. With the University of Tokyo at the apex, universities are conventionally grouped in progressive tiers of competitiveness (Ishikawa, 2009, 168). In practice, however, explicit university-to-university comparison or rigid categorization of institutions hardly existed. Locally based institutions or those with 
specialized areas of strength have played no small role in making Japan's higher education more accessible and affordable for students who live away from the metropolitan areas, some of whom mature into scientists who eventually produce world-class innovations.

The new categorization of universities may risk creating a "compartmentalization" of scholars and their activities, as observed in the Arab East by Hanafi (2011). Divided by the language they use and the social roles they play, elite social scientists in the Arab East have no common fora for encounter or dialogue. While global and "professional" scholars "publish globally but perish locally," becoming alienated from the national society, "public and policy" sociologists who publish in Arabic are condescended to lower social status and publish for the local readership without global access. Japan's new typology of universities may even "engineer" compartmentalization in a national system currently devoid of segmentation by language or type of social responsibilities scholars play. Quests to attain "Top Global” status in Japanese humanities and social science scholarship, if implemented by simply adhering to monolithic norms and values of the world university rankings, therefore "risk rendering professional and critical research more elitist and irrelevant" (Hanafi, 2011, 298).

\section{Conclusion}

The study found that humanities and social science scholars in Japan have not changed their prolific yet parochial publishing practices in a significant way over the past two decades, with a traditional commitment to locally relevant research largely left intact despite signs of emergent policy-driven change. Consequently, international bibliometric indicators of excellence, adopted by most ranking agencies, have remained irrelevant, lacking meanings of value for the majority of Japan's scholars in these fields, with the small but growing exception of younger scholars. Facing the recent decline of Japanese universities in global rankings, 
particularly in the World University Rankings by Times Higher Education (THE), ${ }^{9}$ pressure to "internationalize" targeted, select research universities is destined to mount.

On the other hand, any move to "deindigenize" or "devalue" locally-embedded fields is likely to bring strong repercussions as witnessed by mounting criticism of a recent government notice that suggested restructuring and abolishing humanities and social science departments not only from academics but business leaders and the general public. Whether this episode represents the continuation of a steadfast commitment to and autonomy of national-language scholarship, or the beginning of its erosion, is too early to judge. The global convergence in measures of quality assessment, may be, as Weberians argue, an inevitable step towards the growth of bureaucratic authority and the rationalization of universal credentials for professions (see for example Rank Scholarship [Editorial] 2012, 2-3).

On a positive note, initiatives that give more prominence to international publications and international engagements will facilitate communication between Japanese scholars and those in other countries. Improved communication by use of the same language may result in improved regional understanding and convergence, leading to the rise of, for example, East Asian Anthropology as envisioned by Mathews $(2015,367)$.

The prevalence of and adherence to the world university rankings and accountability politics have altered the production of academic articles in many parts of the world. The changes are not only in medium and language, but about the way knowledge is constructed, produced, and disseminated. For countries with long-standing academic traditions such as Japan, vernacular scholarship in humanities and social sciences has ensured the accessibility and relevance of intellectual knowledge not only for the contemporary local readership but also for generations to come. As academic publications convey cultural and social values, to track their subtle yet emerging changes and often perplexing policy configurations surrounding higher education is 
about understanding core concerns around national identity. Now that identity is, in Amano's (2014) words, faced with the third moment of kaikoku or "opening up" of Japan after the Meiji Restoration in the late $19^{\text {th }}$ century and World War II.

Whether or not Japan can open up without compromising the university's responsibility to domestic constituents depends on policy development, and this can only be done with input from Japan's own academic community. As Slaughter and Cantwell (2012, 603) have suggested for European higher education, university leaders, staff, and policy makers alike need to seek an alternative path for the university to "withdraw from endless competition and reinvent itself as an intellectual and scientific space" in service of the public good.

\section{References}

Altbach, P. G., \& Balán J. (eds.). (2007). World class worldwide: Transforming research universities in Asian and Latin America. Baltimore, MD: Johns Hopkins University Press.

Alatas, S.F. (2003) 'Academic dependency and the global division of labour in the social sciences', Current Sociology 51(6): 599-613.

Amano, I. (2009) Daigaku no tanjō (jō): Teikokudaigaku no jidai (in Japanese) [The birth of universities: The age of imperial universities]. Tokyo: Chūōōron Shinsha.

Amano, I. (2014) Globalization and Higher Education Reforms in Japan: The Obstacles to Greater International Competitiveness, from http://www.nippon.com/en/in-depth/a02801/

Anninos, L.N. (2013) 'Research performance evaluation: Some critical thoughts on standard bibliometric indicators', Studies in Higher Education 39(9): 1-20.

Chou, C. P. (2014) 'Why the SSCI Syndrome Is a Global Phenomenon? ', in C.P. Chou (ed). The SSCI Syndrome in Higher Education. Rotterdam, The Netherlands: Sense Publishers.

Dolan, C. (2007) 'Feasibility study: The evaluation and benchmarking of humanities research in Europe', Humanities in the European Research Area, from http://www.aqu.cat/doc/doc 34869796 1.pdf

Editorial (2012) 'Rank Scholarship'. Comparative Education Review, 56(1), 1-17. http://dx.doi.org/10.1086/663834 
Funamori, M. (2012) 'Nihon oyobi sekai no rombun tōkō jyōkyō no bunseki (in Japanese) [The status of publication and citation of academic articles in Japan and the world]', a presentation at kenkyu kaihatsu hyoka shimpojium [symposium on research development and evaluation]; 6 March, 2012; Japan. from: http://www.mext.go.jp/component/a_menu/science/detail/_icsFiles/afieldfile/2012/05/2 4/1321315_01.pdf

Guo, W. and Ngok, K. (2008) 'The quest for world class universities in China: Critical reflections', Policy Futures in Education 6(5): 545-557.

Hanafi, S. (2011) 'University systems in the Arab East: Publish globally and perish locally vs publish locally and perish globally', Current Sociology 59(3): 291-309.

Hayashi, T. and Tsuchiya, S. (2016) 'Gakumon bunya ni yoru takuetsusei shihyō no tayōsei: tayōna kenkyū seika e no hōshō no hitsuyō' (in Japanese) [Diversity in Excellence Indicators by Discipline and the Need for Differentiated Reward System] in M. Ishikawa (ed). The World University Rankings and Hegemonic Restructuring of Knowledge (in Japanese). Kyoto: Kyoto University Press, pp. 325-345.

Hazelkorn, E. (2013) 'How Rankings are Reshaping Higher Education' in V. Climent, F. Michavila, and M. Ripolles (eds). Los Rankings Univeritarios. Mitos y Realidades.

Hazelkorn, E. (2008) 'Learning to live with league tables and ranking: The experience of institutional leaders', Higher Education Policy 21(2): 193-215.

Huang, A. H. M. (2009) 'Science as ideology: SSCI, TSSCI and the evaluation system of social sciences in Taiwan', Inter-Asia Cultural Studies 10(2): 282-291.

Huisman, J. (2008) 'World-class universities', Higher Education Policy, 21(1), 1-4.

Ishikawa, M. (2009) 'University rankings, global models, and emerging hegemony critical analysis from Japan', Journal of Studies in International Education 13(2): 159-173.

Ishikawa, M. (2011) 'Redefining internationalization in higher education: Global 30 and the making of global universities in Japan', in David B. Willis and Jeremy Rappleye (eds). Reimagining Japanese Education: Borders, Transfers, Circulations, and the Comparative. Oxford, UK: Symposium Books, pp.193-223.

Ishikawa, M. (2014) 'Ranking regime and the future of vernacular scholarship', Education Policy Analysis Archives 22(30). http://dx.doi.org/10.14507/epaa.v22n30.2014

Japan Society for the Promotion of Science (JSPS) (2011) 'Jinbungaku shakaikagaku no kokusaika ni tsuite' (in Japanese) [Internationalization of humanities and social sciences], from https://www.jsps.go.jp/j-kenkyukai/data/02houkokusho/houkokusho.pdf

Jöns, H., and Hoyler, M. (2013) 'Global geographies of higher education: The perspective of world university rankings', Geoforum 46: 45-59. 
Kang, M. (2009) 'State-guided'university reform and colonial conditions of knowledge production', Inter-Asia Cultural Studies, 10(2): 191-205.

Kariya, T. (2015) 'Sūpā gurōbaru daigaku no yukue: gaikokujin kyōintō no kōzai' (in Japanese), [Japan's Plan for "Super Global Universities": The Limits of Japanese-style Globalization], Asteion 82: 38-52.

Kim, K. S. \& Nam, S. (2007) 'The making of a world-class university in the periphery: Seoul National University', in P.G. Altbach \& J. Balán (eds). World Class Worldwide: Transforming Research Universities in Asia and Latin America. Baltimore, MD: Johns Hopkins University Press, pp.122-142.

Lee, H., and Lee, K. (2013) 'Publish (in international indexed journals) or perish: Neoliberal ideology in a Korean university', Language Policy 12(3): 215-230.

Li, Y., and Flowerdew, J. (2009) 'International engagement versus local commitment: Hong Kong academics in the humanities and social sciences writing for publication', Journal of English for Academic Purposes 8(4): 279-293.

Lie, J. (1996) 'Sociology of contemporary Japan', Current Sociology: 44(1): 1-99.

Lo, W. Y. W. (2013) 'University rankings as a zoning technology: A Taiwanese perspective on an imaginary Greater China higher education region', Globalisation, Societies and Education 11(4): 459-478.

Mathews, G. (2015) 'East Asian anthropology in the world', American Anthropologist 117(2): 364-372.

Ministry of Education, Culture, Sports, Science and Technology, Japan (MEXT) (2012) 'Infrastructure development for strengthening the capacity of international scholarly communication', from http://www.mext.go.jp/b_menu/shingi/gijyutu/gijyutu4/toushin/1323857.htm

Mohrman, K. (2008) 'The emerging global model with Chinese characteristics', Higher Education Policy 21: 29-48.

Mok, K. H. (2012) 'Global Aspirations and Strategizing for World-Class Status: New modes of higher-education governance and the emergence of regulatory regionalism in East Asia', in A. R. Nelson and I. P. Wei (eds.) The Global University. New York: Palgrave Macmillan, pp. 25-53.

Ninomiya, A., Knight, J. and Watanabe, A. (2009) 'The Past, Present, and Future of Internationalization in Japan', Journal of Studies in International Education 13(2): 117-124.

Oleksiyenko, A. (2014) 'On the Shoulders of Giants? Global Science, Resource Asymmetries, and Repositioning of Research Universities in China and Russia', Comparative Education Review 58(3): 482-508. 
Paasi, A. (2005) 'Globalisation, academic capitalism, and the uneven geographies of international journal publishing spaces,' Environment and Planning A 37(5): 769-789.

Sawa, T. (2015) 'Humanities under attack', The Japan Times, 23 August.

Scott, J. C. (2012) Two Cheers for Anarchism: Six Easy Pieces on Autonomy, Dignity, and Meaningful Work and Play. Princeton, NJ: Princeton University Press.

Shin, J. C. (2009) 'Building world-class research university: The Brain Korea 21 project', Higher Education 58(5): 669-688.

Shin, J. C., and Cummings, W. K. (2010) 'Multilevel analysis of academic publishing across disciplines: Research preference, collaboration, and time on research', Scientometrics 85(2): 581-594.

Shore, C., and Wright, S. (1999) 'Audit culture and anthropology: Neo-liberalism in British higher education', Journal of the Royal Anthropological Institute 5(4): 557-575.

Sidhu, R. (2005) 'Building a global schoolhouse: International education in Singapore', Australian Journal of Education 49(1): 46-65.

Slaughter, S., \& Cantwell, B. (2012) Transatlantic moves to the market: The United States and the European Union. Higher Education, 63(5): 583-606.

Song, M.-M. \& Tai, H.-H. (2007) 'Taiwan's responses to globalisation: Internationalisation and questing for world class universities', Asia Pacific Journal of Education 27(3): 323-340.

Stack, M. (2016) Global University Rankings and the Mediatization of Higher Education. London: Palgrave Macmillan.

Strathern, M. (2000) Audit Cultures: Anthropological Studies in Accountability, Ethics and the Academy. London: Routledge.

van Raan, A.F.J. (2005) 'Fatal attraction: Conceptual and methodological problems in the ranking of universities by bibliometric methods', Scientometrics 62(1): 133-143.

Wright, S. (2012) 'Ranking universities within a globalised world of competition states: to what purpose, and with what implications for students? ', in H. L. A. J. C. Jacobsen (Eds)., Uddannelseskvalitet $i$ det 21. Arhundrede, Frederiksberg: Samfundslitteratur, pp.79-100.

Yonezawa, A. (2012) 'Japan's university education in social sciences and humanities under globalization', InTech, DOI: 10.5772/38850. 
Table 1. Article Survey: Anthropology

\begin{tabular}{|c|c|c|c|c|}
\hline \multirow{2}{*}{\multicolumn{2}{|c|}{$\begin{array}{l}\text { Year } \\
\text { Number of Researchers }\end{array}$}} & 1993 & 2003 & 2013 \\
\hline & & 4 & 4 & 4 \\
\hline \multicolumn{2}{|c|}{ Total number of articles } & 202 & 79 & 84 \\
\hline \multicolumn{2}{|l|}{ Average per scholar } & 50.5 & 19.8 & 21 \\
\hline \multirow{2}{*}{ Co-authorship } & \multirow{2}{*}{ Not-coauthored } & 202 & 79 & 84 \\
\hline & & $100 \%$ & $100 \%$ & $100 \%$ \\
\hline \multirow{4}{*}{ Title Language } & \multirow{2}{*}{$\mathrm{J}$} & 169 & 47 & 50 \\
\hline & & $83.7 \%$ & $59.5 \%$ & $59.5 \%$ \\
\hline & \multirow{2}{*}{$\mathrm{J} / \mathrm{E}, \mathrm{J} / \mathrm{F}, \mathrm{E}, \mathrm{G} .}$. & 33 & 32 & 34 \\
\hline & & $16.3 \%$ & $40.5 \%$ & $40.5 \%$ \\
\hline \multirow{6}{*}{ Title Relevance } & \multirow{2}{*}{ Borderless } & 92 & 25 & 17 \\
\hline & & $45.5 \%$ & $31.6 \%$ & $20.2 \%$ \\
\hline & \multirow{2}{*}{ Japan } & 45 & 4 & 3 \\
\hline & & $22.3 \%$ & $5.1 \%$ & $3.6 \%$ \\
\hline & \multirow{2}{*}{ Other countries } & 56 & 50 & 64 \\
\hline & & $27.7 \%$ & $63.3 \%$ & $76.2 \%$ \\
\hline \multirow{8}{*}{$\begin{array}{l}\text { Title Geographical } \\
\text { Category }\end{array}$} & \multirow{2}{*}{ National } & 40 & 4 & 2 \\
\hline & & $19.8 \%$ & $5.1 \%$ & $2.4 \%$ \\
\hline & \multirow{2}{*}{ International } & 64 & 57 & 69 \\
\hline & & $31.7 \%$ & $72.2 \%$ & $82.1 \%$ \\
\hline & \multirow{2}{*}{ Overlapping } & 11 & 2 & 1 \\
\hline & & $5.4 \%$ & $2.5 \%$ & $1.2 \%$ \\
\hline & \multirow{2}{*}{ Borderless } & 87 & 16 & 12 \\
\hline & & $43.1 \%$ & $20.3 \%$ & $14.3 \%$ \\
\hline \multirow{6}{*}{ Abstract Language } & \multirow{2}{*}{$\mathrm{J}$} & 2 & 3 & 6 \\
\hline & & $1.0 \%$ & $3.8 \%$ & $7.1 \%$ \\
\hline & \multirow{2}{*}{$\mathrm{J} / \mathrm{E}, \mathrm{J} / \mathrm{F}, \mathrm{E}$} & 12 & 21 & 29 \\
\hline & & $5.9 \%$ & $26.6 \%$ & $34.5 \%$ \\
\hline & \multirow{2}{*}{ N.A. } & 188 & 55 & 49 \\
\hline & & $93.1 \%$ & $69.6 \%$ & $58.3 \%$ \\
\hline \multirow{6}{*}{ Journal Language } & \multirow{2}{*}{$\mathrm{J}$} & 198 & 73 & 78 \\
\hline & & $98.0 \%$ & $92.4 \%$ & $92.9 \%$ \\
\hline & \multirow{2}{*}{$\mathrm{E}$} & 3 & 6 & 6 \\
\hline & & $1.5 \%$ & $7.6 \%$ & $7.1 \%$ \\
\hline & \multirow{2}{*}{$\mathrm{G}$} & 1 & & \\
\hline & & $0.5 \%$ & & \\
\hline & & 198 & 79 & 84 \\
\hline Journal Origin & Japan & $98.0 \%$ & $100 \%$ & $100 \%$ \\
\hline 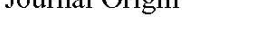 & Othor countriec & 4 & & \\
\hline & Uner countries & $2.0 \%$ & & \\
\hline & National & 198 & 79 & 84 \\
\hline Journal & National & $98.0 \%$ & $100 \%$ & $100 \%$ \\
\hline Category & International & 4 & & \\
\hline & International & $2.0 \%$ & & \\
\hline
\end{tabular}

$\mathrm{E}=$ English, $\mathrm{F}=$ French, $\mathrm{G}=$ German, $\mathrm{J}=$ Japanese, $\mathrm{S}=$ Spanish, N.A. =Not Available. 
Table 2: Article Survey: Education Policy

\begin{tabular}{|c|c|c|c|c|}
\hline \multicolumn{2}{|c|}{ Year } & 1993 & 2003 & 2013 \\
\hline \multicolumn{2}{|l|}{ Number of Researchers } & 6 & 5 & 4 \\
\hline \multicolumn{2}{|l|}{ Total number of articles } & 434 & 250 & 250 \\
\hline \multicolumn{2}{|l|}{ Average per scholar } & 72.3 & 50 & 62.5 \\
\hline \multirow{2}{*}{ Co-authorship } & \multirow{2}{*}{ Not-coauthored } & 430 & 248 & 249 \\
\hline & & $99.1 \%$ & $99.2 \%$ & $99.6 \%$ \\
\hline \multirow{4}{*}{ Title Language } & \multirow{2}{*}{$\mathbf{J}$} & 340 & 156 & 172 \\
\hline & & $78.3 \%$ & $62.4 \%$ & $68.8 \%$ \\
\hline & \multirow{2}{*}{$\mathrm{J} / \mathrm{E}, \mathrm{J} . \mathrm{F}, \mathrm{E} \ldots$} & 94 & 94 & 78 \\
\hline & & $21.7 \%$ & $37.6 \%$ & $31.2 \%$ \\
\hline \multirow{6}{*}{ Title Relevance } & \multirow{2}{*}{ Borderless } & 96 & 27 & 22 \\
\hline & & $22.1 \%$ & $10.9 \%$ & $8.8 \%$ \\
\hline & \multirow{2}{*}{ Japan } & 333 & 173 & 148 \\
\hline & & $76.7 \%$ & $69.2 \%$ & $59.2 \%$ \\
\hline & \multirow{2}{*}{ Other countries } & 5 & 50 & 80 \\
\hline & & $1.2 \%$ & $20.0 \%$ & $32.0 \%$ \\
\hline \multirow{8}{*}{$\begin{array}{l}\text { Title Geographical } \\
\text { Category }\end{array}$} & \multirow{2}{*}{ National } & 332 & 174 & 139 \\
\hline & & $76.5 \%$ & $69.6 \%$ & $55.6 \%$ \\
\hline & \multirow{2}{*}{ International } & 5 & 46 & 78 \\
\hline & & $1.2 \%$ & $18.4 \%$ & $31.2 \%$ \\
\hline & \multirow{2}{*}{ Overlapping } & 2 & 3 & 5 \\
\hline & & $0.5 \%$ & $1.2 \%$ & $2.0 \%$ \\
\hline & \multirow{2}{*}{ Borderless } & 95 & 27 & 18 \\
\hline & & $21.9 \%$ & $10.8 \%$ & $7.2 \%$ \\
\hline \multirow{6}{*}{ Abstract Language } & \multirow{2}{*}{$\mathrm{J}$} & & & 1 \\
\hline & & & & $0.4 \%$ \\
\hline & \multirow{2}{*}{$\mathrm{J} / \mathrm{E}, \mathrm{E}, \mathrm{F} \ldots$} & 49 & 54 & 41 \\
\hline & & $11.3 \%$ & $21.6 \%$ & $16.4 \%$ \\
\hline & \multirow[t]{2}{*}{ N.A. } & 385 & 196 & 208 \\
\hline & & $88.7 \%$ & $78.4 \%$ & $83.2 \%$ \\
\hline \multirow{4}{*}{ Journal Language } & \multirow{2}{*}{$\mathrm{J}$} & 432 & 248 & 244 \\
\hline & & $99.5 \%$ & $99.2 \%$ & $97.6 \%$ \\
\hline & \multirow{2}{*}{ E } & 2 & 2 & 6 \\
\hline & & $0.5 \%$ & $0.8 \%$ & $2.4 \%$ \\
\hline \multirow{4}{*}{ Journal Origin } & & 432 & 248 & 244 \\
\hline & Japan & $99.5 \%$ & $99.2 \%$ & $97.6 \%$ \\
\hline & Other countriec & 2 & 2 & 6 \\
\hline & Other countries & $0.5 \%$ & $0.8 \%$ & $2.4 \%$ \\
\hline & & 432 & 248 & 244 \\
\hline Journal Geographical & National & $99.5 \%$ & $99.2 \%$ & $97.6 \%$ \\
\hline Category & & 2 & 2 & 6 \\
\hline & International & $0.5 \%$ & $0.8 \%$ & $2.4 \%$ \\
\hline
\end{tabular}

$\mathrm{E}=$ English, $\mathrm{F}=$ French, $\mathrm{G}=$ German, J=Japanese, $\mathrm{S}=$ Spanish, N.A. =Not Available.

Table 3. Books vs. articles: Publishing by selected senior scholars in both fields

\begin{tabular}{|l|c|c|c|c|}
\hline & \multicolumn{2}{|c|}{ Anthropology } & \multicolumn{2}{c|}{ Education Policy } \\
\hline Scholars & A & B & C & D \\
\hline Number of Books \& edited volumes & 27 & 17 & 67 & 25 \\
\hline Translated books & 4 & - & 5 & - \\
\hline Articles and others & 152 & 27 & 223 & 82 \\
\hline
\end{tabular}

1 Neoliberal policies are among many factors and by no means the only reason for the intensifying global race for competitiveness. Kang $(2009,192)$, for instance, states that the Korean government's university reform policy is more "state market-ist" rather than neoliberalist. 
2 This study is part of a larger international comparative project on the impact of global competition on local publication and the scholarship. Please see the preface of this issue and the next section of this article for the details of the methodology.

3 The total number of scholars and articles does not equal the total figures in Table 1 and 2 as there are some duplicates. Some scholars remained in the same faculty position during different reference years.

4 "Title Relevance" stands for the country of the research content. For example, if the article is about policy concerning incoming international students in China, the Title Relevance is China. "Borderless" is for a borderless or purely theoretical article. Regarding "Title Geographic Category," "Borderless" is the same as above. This criterion identifies whether the research scope of an article is more international or locally focused. For example, a comparison between Japanese and American immigration policies falls into "International." "Journal Language" denotes the official language of a journal. In Japan, Japanese is the official language for most journals. "Journal Origin" denotes the country in which the journal is registered. 5 http://www.jsps.go.jp/j-sgu/data/shinsa/h26/h26_sgu_kekka_e.pdf

6 The next six-year "medium-term" begins in 2016 for all national universities in Japan, for which they are required to submit plans for approval by the MEXT, and subsequently evaluated for the achievements during the period of the term (cf. Yonezawa, 2012). The performance of each term is clearly tied to funding allocation in subsequent years and/or term.

7 The MEXT vehemently denied the allegation and subsequently released a statement saying that their intention was not to abolish humanities and social sciences or convert them to utilitarian science fields. Rather, it argued these fields tend to be narrow-focused and inward-looking, thus needing a shakeup to meet the demands of students and the society.

(http://www.mext.go.jp/component/a_menu/education/detail/_icsFiles/afieldfile/2015/10/01/1362382_2.p df).

8 They are the universities of Chiba, Hiroshima, Hitotsubashi, Hokkaido, Kanazawa, Kobe, Kyoto, Kyushu, Nagoya, Okayama, Osaka, Tohoku, Tsukuba, and Tokyo, Tokyo Institute of Technology, and Tokyo University of Agriculture and Technology. The underlined are the Top Global University project awardees. 9 In the Times Higher Education (THE) rankings released in 2015, almost all Japanese universities dropped their positions. The University of Tokyo fell from 23 to 45, Kyoto University from 59 to 88, and most others disappeared from the list of the top 200 universities, reportedly due to a change in the methodology that evaluates research quality and productivity. 